\title{
PENGARUH KOMPENSASI MANAJEMEN, KECURANGAN LAPORAN KEUANGAN DAN TATA KELOLA PERUSAHAAN TERHADAP KUALITAS LABA
}

Oleh :

Nur Anissa, SE.,M.Si.,Ak.,CA

Fakultas Ekonomi Program Studi Akuntansi Universitas Satya Negara Indonesia

\begin{abstract}
ABSTRAK
Laba memainkan peran penting dalam laporan keuangan jika di dalamnya mengandung informasi tentang fenomena utama perusahaan tersampaikan kepada para pengguna dengan baik. Manfaat potensial informasi adalah hal penting dimana manfaat ditentukan oleh kualitas informasi. Penelitian ini bertujuan untuk mendapatkan bukti empiris mengenai faktor-faktor yang mempengaruhi kualitas laba, yaitu kompensasi manajemen, kecurangan laporan keuangan dan tata kelola perusahaan. Dalam penelitian ini, tata kelola perusahaan diproksi dengan efektifitas komite audit.

Sampel yang digunakan dalam penelitian ini adalah perusahaan manufaktur yang terdaftar di BEI pada periode 2010 sampai 2011 dengan jumlah sampel sebanyak 110. Metode analisis yang digunakan adalah regresi linear berganda.

Hasil analisis menunjukkan bahwa kompensasi manajemen berpengaruh negatif terhadap kualitas laba dan efektifitas komite audit berpengaruh positif terhadap kualitas laba. Sedangkan, hipotesis kecurangan laporan keuangan berpengaruh negatif terhadap kualitas laba ditolak.
\end{abstract}

Kata Kunci: kompensasi manajemen, kecurangan laporan keuangan, tata kelola perusahaan, kualitas laba 


\section{PENDAHULUAN}

\section{Latar Belakang Masalah}

Beasley, Carcello, Hermanson, dan Neal (2010) menemukan bahwa kecurangan pelaporan keuangan umumnya terkait dengan manajemen puncak, dan $72 \%$ dari kasus yang ada menunjukkan adanya keterlibatan Chief Excecutive Officer (CEO) dan 65\% dari kasus yang ada melibatkan Chief Financial Officer (CFO). Hal ini sejalan dengan pernyataan Boyle, Carpenter dan Hermanson (2012) bahwa kecurangan laporan keuangan umumnya dilakukan oleh CEO dan CFO yang mungkin memaksa karyawan dibawahnya untuk berpartisipasi dalam melakukan kecurangan dan Hogan et.al. (2008) yang menyatakan bahwa insentif manajemen mendorong terjadinya manajemen laba. Sementara itu, kecurangan dalam laporan keuangan (KDLK) di Indonesia diindikasikan dengan makin bertambahnya perusahaan yang mendapat teguran dan sanksi dari Badan Pengawas Modal, pada tahun 2008 perusahaan mendapat teguran hanya 1 perusahaan dan naim sangat tajam pada tahun 2011 tidak kurang dari 17 perusahaan mendapatkan teguran dan sanksi.

Kecurangan penyusunan laporan keuangan menunjukkan bahwa laporan keuangan tidak sesuai dengan prinsip akuntansi yang berterima umum (GAAP). Kecurangan penyusunan laporan keuangan menunjukkan lemahnya sistem pengendalian internal perusahaan (Kinney dan McDaniel, 1989). Penyajian Kembali sebagai salah satu bentuk kecurangan laporan keuangan memiliki dampak yang signifikan pada penilaian perusahaan (Srinivasan, 2005). Wu (2002) melaporkan bahwa koefisien respon laba menurun ketika terjadi penyajian kembali, hal ini mengindikasikan hilangnya kepercayaan dalam kualitas laba perusahaan.

Literatur teori akuntansi positif menyatakan bahwa kompensasi manajer mendorong sikap oportunis manajeman untuk membuat kebijakan akuntansi yang dapat menaikkan laba, agar mendapatkan kompensasi. Kompensasi manajeman memberikan sinyal negatif bagi pasar, bahwa manajemen perusahaan bersikap oportunis dengan menaikkan laba perusahaan yang berdampak pada turunnya kualitas laba (Srinivasan, 2005). Namun demikian, penelitian terdahulu menunjukkan hasil yang variatif, perspektif alignment membuktikan kompensasi berhubungan positif dengan nilai perusahaan, kinerja perusahaan dan informasi yang berkualitas (Murphy, 2002; dan Nagar et.al, 2002). Sementara itu perspektif entrechment mendukung teori keagenan yang membuktikan adanya sikap oportunis manajemen sehingga menghasilkan hasil yang disfungsional (Bebchuk dan Fried, 2006). 
Sebagian besar penelitian kecurangan pelaporan keuangan terkait dengan kompensasi manajerial baik kompensasi kas maupun kompensasi saham. Kompensasi kas yang berlebihan atas manajeman dikaitkan dengan kondisi perusahaan yang underperformance. Hal ini mengindikasikan adanya gejala bahwa perusahaan dalam kondisi kronis karena manajemen tidak peduli dengan kepentingan pemegang saham (Brick et al., 2006). Selanjutnya, perusahaan lebih memilih opsi saham sebagai kompensasi manajemen karena menganggap bahwa pilihan ini menyelaraskan kepentingan manajemen dengan pemegang saham. Opsi saham membuktikan bahwa manajemen mendukung investasi berisiko tinggi yang dapat meningkatkan nilai opsi melalui kenaikan harga saham yang juga meningkatkan keuntungan bagi pemegang saham (Hoi \& Robin, 2004). Manajemen yang dikompensasi dengan opsi saham tidak memiliki modal yang berisiko, sehingga tidak terbebani resiko investasi terkait kepentingan keuangan pemegang saham dalam jangka panjang (Winter, 2003).

Penelitian terdahulu tentang kompensasi manajemen dan kecurangan laporan keuangan memberikan bukti yang tidak konklusif. Efendi et al. (2007) menggunakan sampel perusahaan yang menyajikan kembali laporan keuangan menemukan bukti bahwa terjadinya salah saji laporan keuangan meningkat ketika CEO memiliki jumlah opsi saham yang lebih besar. Namun demikian, pernyataan ini bertolak belakang dengan hasil penelitian Amstrong et.al. (2010) yang menemukan bahwa kecurangan akuntansi lebih sedikit terjadi pada perusahaan yang insentif ekuitasnya lebih besar. Erickson et.al. (2006) dalam penelitiannya tidak berhasil menunjukkan bukti yang konsisten mendukung kesimpulan bahwa probabilitas kecurangan akuntansi meningkat pada ekuitas eksekutif. Bukti yang tidak konklusif ini mengindikasikan adanya kemungkinan bahwa kompensasi manajemen berpengaruh tidak langsung terhadap kecurangan akuntansi atau adanya hubungan yang komplek diantara keduanya (Trompeter, et.al, 2012).

Sesuai dengan teori keagenan (Fama dan Jensen 1983; Jensen 1993) yang dibuktikan oleh Beasley (1996); Dechow et al (1996) yang membuktikan peran monitoring BOD dalam mereduksi praktek kecurangan pelaporan keuangan. Namun demikian, jika tata kelola gagal memainkan perannya, maka hal ini menunjukkan adanya masalah keagenan serius antara manajer perusahaan dan pemegang saham yang mengandalkan tata kelola perusahaan yang baik dalam memantau aktifitas manajer.

\section{Rumusan Masalah}

1. Apakah kompensasi manajemen berpengaruh terhadap kualitas laba?

2. Apakah kecurangan pelaporan keuangan berpengaruh terhadap kualitas laba?

3. Apakah tata kelola perusahaan berpengaruh terhadap kualitas laba? 


\section{TINJAUAN PUSTAKA DAN PENGEMBANGAN HIPOTESIS \\ Teori Keagenan}

Problem agensi timbul karena ada perbedaan tujuan antara agent dengan principle (Jensen \& Meckling, 1976). Konflik kepentingan menyebabkan problem agensi antara manajer dan pemilik, ketika risiko yang ditanggung oleh pemilik terpisah dari manajeman. Dengan bahasa yang berbeda, Berle dan Means (1932) mengungkapkan bahwa problem agensi timbul ketika pemilik terpisah dari manajeman (control). Manajer secara efektif mengendalikan kekayaan perusahaan tetapi pada umumnya tidak memiliki equitas yang signifikan di perusahaan.

Teori agensi berlaku dalam kondisi-kondisi tertentu. Agency theory menggunakan tiga asumsi sifat dasar manusia, yaitu : manusia umumnya mementingkan diri sendiri, manusia memiliki daya pikir terbatas mengenai persepsi masa depan, dan manusia cenderung menghindari risiko (Eisenhardt, 1989). Selain itu, baik principle maupun agen diasumsikan bertindak rasional dan berupaya untuk memaksimalkan utilitasnya, oleh karena itu, masing-masing pihak akan senantiasa bertindak untuk kepentingannya sendiri.

Jensen dan Meckling (1976) mengungkapkan bahwa perbedaan kepentingan antara agen dan prinsipal menimbulkan konflik kepentingan antara manajershareholder. Baik prinsipal maupun agen secara rasional sama-sama bertindak untuk kepentingannya sendiri dan berupaya untuk memaksimalkan utilitasnya sendiri. Sehubungan dengan itu, maka harus diyakini bahwa tidak selamanya manajer akan bertindak untuk kepentingan terbaik principal. Dalam konteks teori agensi terkait dengan kecurangan dalam laporan keuangan, manajer akan bersifat oportunis untuk membela kepentingannya (Deegan, 2004) dengan cara melakukan kecurangan atas laporan keuangan agar kinerja individunya terlihat baik.

\section{Kecurangan Laporan Keuangan}

Kecurangan laporan keuangan adalah tindakan yang sengaja dilakukan

oleh manajemen untuk memuaskan investor dan kreditor melalui laporan keuangan yang sesungguhnya menyesatkan (Elliott dan Willingham, 1980; Nguyen, 2008) American Institute of Certified Public Accountants (AICPA) mendefinisikan suatu tindakan disengaja yang menghasilkan salah saji material dalam laporan keuangan yang akan diaudit (AICPA, 2002). Sementara itu, Instiute Internal of Auditors (IIA) mengatakan fraud adalah setiap tindakan ilegal yang ditandai dengan segala tipu daya, penyembunyian, atau pelanggaran kepercayaan. Tindakan ini tidak bergantung kepada adanya ancaman kekerasan atau kekuatan fisik. Penipuan yang dilakukan oleh organisasi bertujuan untuk mendapatkan uang, properti atau layanan, menghindari pembayaran atau kerugian jasa, dan atau untuk mengamankan kepentingan pribadi. 
Tiga karakteristik umum yang dikaitkan dengan pelanggaran kepercayaan, yaitu: 1) tekanan masalah keuangan, 2) kesempatan untuk melanggar kepercayaan, dan 3) kemampuan untuk merasionalisasi pelanggaran kepercayaan sebagai tindakan yang dibenarkan. Pelanggaran kepercayaan atau kecurangan memiliki tiga elemen kunci yang berbasis tindak pidana, penyembunyian, dan konversi atau pemanfaatan bagi pelaku (Dorminey et. al., 2012).

Tindakan merupakan eksekusi dan metodologi kecurangan, seperti kecurangan laporan keuangan, skimming, korupsi (misal: suap), dan pencucian uang. Sementara itu, penyembunyian merupakan tindakan yang disengaja untuk menyembunyikan tindak pidana. Beberapa metode umum penyembunyian mencakup pengubahan dokumen, pencatatan jurnal yang tidak semestinya, rekonsiliasi yang dimanipulasi dan penghancuran dokumen. Sedangkan konversi secara hukum didefinisikan sebagai melanggar hukum dengan melakukan perampasan harta orang lain atau sebagai transfer nilai dengan pelaku, termasuk uang, mobil, rumah, liburan, dan kemewahan lainnya mungkin tidak terjangkau bagi pelaku tanpa melakukan tindakan kecurangan. Bentuk kecurangan laporan keuangan yang berbasis konversi adalah pemanfaatan dari nilai saham yang lebih tinggi (misalnya, Enron, Satyam Computer Services), peningkatan gaji, dan bonus kinerja (Dorminey et. al., 2012).

\section{Kompensasi Eksekutif}

Pemegang saham tidak dapat mengamati dan memantau upaya seorang eksekutif dengan sempurna sehingga mereka mengadakan kontrak kompensasi berdasarkan hasil yang dapat diamati seperti laba akuntansi atau harga saham (Johnson, Ryan dan Tian, 2005). Pada umumnya komponen kontrak kompensasi berisi empat dasar, yaitu gaji, bonus tahunan, opsi saham dan saham terbatas. Di antara empat komponen tersebut gaji dan bonus merupakan komponen dari kompensasi kas. Sedangkan, opsi saham dan saham terbatas merupakan komponen kompensasi saham. Kompensasi kas pada umumnya didasarkan atas laba akuntansi tahun berjalan sehingga memberikan insentif jangka pendek kepada manajemen. Sebaliknya, kompensasi ekuitas didasarkan pada harga saham dan memberikan insentif jangka panjang.

Coles et. al. (2006) menyatakan beberapa motivasi pemberian kompensasi ekuitas. Pertama, pemberian kompensasi ekuitas ditujukan untuk mendorong manajer untuk memaksimalkan kekayaan pemegang saham dengan cara mengalihkan kekayaan manajer menjadi berdasarkan harga saham. Selanjutnya, pemberian kompensasi ekuitas digunakan untuk memotivasi manajer yang memiliki informasi superior tentang perusahaan untuk bertindak bagi kepentingan terbaik pemegang saham. Lalu, pemberian kompensasi ekuitas ini untuk menjaga kas perusahaan dan pemberian opsi saham tidak diakui sebagai beban. 


\section{Tata Kelola Perusahaan}

Tata kelola perusahaan berupaya untuk mengurangi masalah bahaya moral (moral hazard). Jensen (1993) berpendapat bahwa terdapat empat hal untuk menciptakan tata kelola perusahaan yang efektif, yaitu hukum dan sistem peraturan, mekanisme pengendalian eksternal, produk dan faktor pasar, dan sistem pengendalian internal yang dipimpin oleh dewan direksi. Sistem hukum dan peraturan termasuk didalamnya adalah pemantauan dalam bentuk pengawasan regulasi eksternal.

Mekanisme pengendalian eksternal mencakup kemampuan pasar modal untuk menangani likuidasi dan pengambilalihan yang merupakan bentuk utama kegagalan untuk memaksimalkan nilai pemegang saham (Fama, 1980). Sedangkan, produk dan faktor pasar termasuk kompetisi produk dan jasa perusahaan yang merupakan bentuk dari pasar tenaga kerja manajerial eksternal dan internal (Fama, 1980). Sementara itu, sistem pengendalian internal mencakup kegiatan dewan direksi, kompensasi eksekutif, opsi saham, dan kepemilikan kepentingan yang semuanya ditujukan untuk menyelaraskan keinginan manajer untuk keuntungan pribadi serupa dengan motivasi pemegang saham (Jensen \& Meckling, 1976).

Selama tiga dekade terakhir, gagasan direksi independen menjadi penting, terutama dengan regulator pasar modal dan banyak pendukung tata kelola perusahaan (Farrar, 2001). Analis keuangan umumnya menyarankan bahwa representasi direksi independen pada dewan komisaris meningkatkan efektivitas dewan dalam memantau manajer dan melakukan pengendalian atas nama pemegang saham (Fama \& Jensen, 1983).

\section{Kualitas Laba}

Pendefinisian tentang kualitas laba baik dari para peneliti maupun antara peneliti dan praktisi tidak mempunyai kesepakatan (konsensus) (Penman dan Zhang, 2002; Bao dan Bao, 2004). Beberapa hal yang dipertimbangkan sebagai kualitas laba meliputi dasar kinerja ekonomik sebuah perusahaan (seperti standar akuntansi yang melaporkan berdasarkan fenomena). Pertimbangan lain untuk kualitas laba mengacu pada bagaimana laba akuntansi dapat dengan baik menyampaikan informasi tentang fenomena utama perusahaan. Selanjutnya, manfaat potensial informasi adalah penting, dimana manfaat ditentukan oleh kualitas informasi.

Cornell dan Landsman (2003) mengidentifikasikan tiga ukuran terbaik untuk kualitas laba yaitu metode value relevan, metode information contents, dan metode predictive ability. Kualitas laba menunjukkan kemampuan pelaporan laba dalam merefleksikan laba perusahaan yang sebenarnya sehingga dapat bermanfaat untuk memprediksi laba yang akan datang. 
Pendekatan value relevance tidak dilakukan dengan basis event windows dan kelemahannya adalah bahwa metode ini banyak sekali pilihannya dan harus dibuat asumsi untuk setiap model yang dipilih (Brown dan Sivakumar, 2001). Information content mempunyai kekuatan yang lebih dibanding value relevance karena pendekatan ini menggunakan short windows terkait dengan perubahan harga atas earning surprise yang memungkinkan kerubahan harga tersebut sebagai akibat dari informasi laba. Kelemahan pendekatan information contents adalah penggunaan model benchmark yang benar untuk abnormal return dan adanya kontaminasi event.

Sementara itu, Penman dan Zhang (2002) mengungkapkan bahwa laba dikatakan berkualitas baik jika laba tersebut merupakan indikator yang baik untuk laba yang akan datang. Laba yang sustainable adalah laba berkualitas tinggi, sebagaimana sering diacu oleh para analis. Sedangkan, Collin dan Salatka (1993) mempertimbangkan earning respon coefficient (ERC) sebagai proksi untuk laba berkualitas. Hasil penelitian ini tidak conclusive, karena ERC dapat dihasilkan dari faktor makro ekonomi. Dengan pendekatan lain, Wild (1996) menggunakan variabilitas return di antara pengumuman laba untuk proksi kualitas laba.

\section{Pengaruh Kompensasi terhadap Kualitas Laba}

Dalam perspektif teori keagenan, kompensasi mendorong oportunistik manajeman untuk bertindak sesuai dengan kepentingannya sendiri. Manajemen yang yang bersikap oportunis akan cenderung melakukan apapun agar kekayaannya dapat bertambah, sehingga manajer oportunis akan bertindak curang agar kinerjanya dianggap baik. Hal didukung oleh Bebchuck dan Fried (2004) yang menggunakan kekuasaan manajerial untuk menjelaskan kompensasi CEO dan menyatakan bahwa CEO menggunakan kekuasaannya untuk mendapatkan kompensasi yang lebih dari cukup. Hal ini sejalan dengan perspektif yang membuktikan adanya sikap oportunis manajemen sehingga memberikan hasil yang disfungsional (Bebchuk dan Fried, 2006).

Perilaku disfungsional manajeman atas sikap oportunis kompensasi manajeman memberikan sinyal negatif bagi pasar, sehingga akan berdampak pada persepsi investor atas laba yang diinformasikan oleh manajeman. Semakin tinggi kompensasi maka kepercayaan atas informasi laba semakin rendah. Hal ini menunjukkan bahwa manajemen perusahaan yang bersikap oportunis untuk mendapatkan kompensasi dengan cara menaikkan laba perusahaan akan berdampak pada turunnya kualitas laba (Srinivasan, 2005).

H1: Kompensasi berpengaruh negatif pada kualitas laba 


\section{Pengaruh Kecurangan Laporan Keuangan terhadap Kualitas Laba}

Kualitas laba memberikan sinyal tentang kinerja perusahaan. Teori agensi menyatakan bahwa manajer akan bersikap oportunis mementingkan dirinya sendiri melalui asimetri informasi dengan melakukan kecurangan dalam laporan keuangan perusahaan agar kinerjanya terlihat baik. Kualitas laba dapat dilihat dari hubungan antara laba dengan return saham (Collins, Maydew dan Weiss, 1997; Francis dan Schipper, 1999; dan Ecker, Francis, and Kim, 2006), sehingga besarnya laba akan berpengaruh terhadap return saham. Namun demikian, laba yang dihasilkan dari kecurangan tidak mencerminkan kinerja perusahaan yang sesungguhnya. Bahkan Kalbers (2009) mempertanyakan kualitas laba yang tinggi. Kalbers (2009) mengatakan bahwa kualitas laba (earnings quality) dapat dianggap sebagai kualitas tinggi yang menuju kecurangan (fraud). Kecurangan laporan keuangan mengindikasikan bahwa perusahaan mempunyai kinerja yang kurang baik sehingga melakukan kecurangan agar kinerja terlihat baik baik. Kecurangan laporan keuangan memberi sinyal bahwa kualitas informasi laporan keuangan tidak baik dan akan direspon tidak baik juga oleh para investor.

H2: Kecurangan laporan keuangan berpengaruh negatif terhadap kualitas laba

\section{Pengaruh Efektifitas Komite Audit terhadap Kualitas Laba}

Niu (2006) menyatakan bahwa reliabilitas laporan keuangan merupakan bagian dari independensi dan integritas proses audit. Dalam seluruh tahapan audit atas laporan keuangan, komite audit memegang peran yang sangat penting. Komite audit bertanggung jawab untuk merekomendasikan pemilihan eksternal auditor, memastikan keandalan dan kualitas praktek akuntansi dan pengendalian internal, dan mengawasi independensi audit eksternal dari manajemen (Petra, 2007). Komite audit bukan hanya berkewajiban untuk merekomendasikan pemilihan auditor eksternal, tetapi juga mengawasi kinerja auditor (Chen et.al. 2014). Sehubungan dengan peran komite audit untuk mengawasi independensi dan kinerja auditor, maka efektivitas komite audit menjadi sangat penting. Hal ini disebabkan laporan keuangan yang telah diaudit tunduk pada pengawasan dan persetujuan dari komite audit sebelum dipublikasikan (Carcello dan Neal 2000). Selanjutnya Anderson (2003) mengungkapkan bahwa persepsi pasar atas angka akuntansi adalah fungsi dari tata kelola perusahaan. Komite audit independen dapat meningkatkan keakuratan informasi keuangan perusahaan, sehingga pasar lebih mengandalkan informasi yang dirilis oleh perusahaan yang mempunyai proporsi komite audit independen yang lebih banyak (Al-Dhamari dan Ku Ismail, 2013). 
Penelitian terdahulu yang menguji hubungan komite audit dengan kualitas laba memberikan hasil yang tidak konsisten. Chang dan Sun (2009) membuktikan bahwa pengungkapan komite audit independen berhubungan positif dengan keinformativan laba pada tingkat signifikansi 10\%. Al-Dhamari dan Ku Ismail, (2013) meneliti di perusahaan yang terdaftar di bursa Malaysia juga membuktikan bahwa efektivitas komite audit berpengaruh terhadap keinformativan laba. Cormier (2010) membuktikan bahwa jumlah komite audit perpengaruh positif terhadap volatilitas return saham, yang berarti bahwa komite audit dapat mengurangi asimetri informasi antara manajemen dengan investor.

H3: Efektivitas komite audit berpengaruh positif terhadap kualitas laba

\section{METODE PENELITIAN}

\section{Populasi dan Sampel}

Populasi data yang digunakan dalam penelitian ini adalah perusahaan yang dikategorikan sebagai kelompok perusahaan manufaktur yang terdaftar di Bursa Efek Indonesia antara tahun 2010 sampai dengan tahun 2011. Data yang digunakan adalah laporan keuangan tahunan dan annual report yang telah diaudit oleh auditor independen.

Pengambilan sampel dilakukan menggunakan metode purposive sampling dengan kriteria-kriteria tertentu, yaitu:

1. Perusahaan terdaftar di Bursa Efek Indonesia (BEI) dengan periode pengamatan 2010-2011.

2. Perusahaan menerbitkan laporan keuangan dan annual report dari periode 2010 sampai periode 2011 yang telah diaudit

3. Perusahaan memiliki data yang lengkap.

Sampel yang digunakan dalam penelitian ini adalah laporan keuangan dan data keuangan dari perusahaan manufaktur di Indonesia antara tahun 2010 sampai dengan tahun 2011 sebanyak 110 sampel data perusahaan. Data-data sampel ini diperoleh melalui situs Bursa Efek Indonesia (www.idx.co.id).

\section{Operasionalisasi dan Pengukuran Variabel}

\section{Variabel Kompensasi}

Variabel ini diukur menggunakan variabel dummy, yaitu memberikan nilai 1 untuk perusahaan yang memberikan insentif kas dan nilai 0 untuk perusahaan yang tidak memberikan insentif dalam bentuk kas. 


\section{Varibael Efektifitas Komite Audit}

Sesuai dengan "Pedoman Pembentukan Komite Audit yang Efektif", suatu komite audit sedikitnya mengadakan rapat sekali dalam tiga bulan. Dalam pertemuan ini akan dibahas kinerja komite audit dalam menjalankan fungsinya, yaitu melakukan pengawasan internal, mengawasi pelaporan keuangan dan memeriksa laporan keuangan, dan yang terakhir adalah mengawasi penerapan tata kelola perusahaan. Komite audit yang efektif, yaitu komite audit yang rajin melakukan pertemuan (rapat), akan lebih mampu dalam memonitor terjadinya tindakan manajemen laba. Variabel dalam penelitian ini diukur dengan menggunakan jumlah pertemuan (rapat) komite audit dalam satu tahun atau satu periode.

\section{Variabel Kecurangan Laporan Keuangan}

Variabel ini mewakili ada atau tidaknya kecurangan akuntansi yang dilakukan oleh perusahaan. Bila terdapat perusahaan yang terdaftar dalam Daftar Kasus Bapepam-LK diberi nilai 1. Sedangkan perusahaan yang tidak terdapat dalam Daftar Kasus Bapepam-LK diberi nilai 0 (nol).

\section{Variabel Kualitas Laba}

Kualitas laba diukur menggunakan Earnings Response Coefficients (ERC). ERC mengukur besarnya abnormal return saham dalam merespon komponen kejutan dari laba yang dillaporkan perusahaan (Scott, 2000). Besarnya ERC diperoleh dengan melakukan beberapa tahap perhitungan.Tahap pertama menghitung Cumulative Abnormal Return (CAR), tahap kedua menghitung Unexpected Earning (UE), lalu angka ERC didapat dari nilai slope $\alpha_{1}$ dalam hubungan antara CAR dan UE.

1) Cumulative Abnormal Return (CAR)

Cumulative Abnormal Return merupakan proksi dari harga saham atau reaksi pasar.

Dimana:

$$
\mathrm{CAR}_{\mathrm{i}, \mathrm{t}}=\boldsymbol{\Sigma} \mathbf{A b}(\mathbf{R})
$$

CAR $_{\mathrm{i}, \mathrm{t}} \quad$ : return abnormal kumulatif perusahaan i selama periodetertentu

$\mathrm{Ab}(\mathrm{R}) \quad$ : abnormal return saham ke-i pada periode ke-t

Dimana:

$$
\operatorname{Ab}(\mathbf{R})=\mathbf{R}_{\mathbf{i}, \mathrm{t}}-\mathbf{E}\left(\mathbf{R}_{\mathbf{i}}\right)
$$

$\mathrm{Ab}(\mathrm{R}) \quad$ : Abnormal return saham ke-i pada periode ke-t

$\mathrm{R}_{\mathrm{i}, \mathrm{t}} \quad$ : Actual return saham ke-i pada periode ke- $\mathrm{t}$

$\mathrm{E}\left(\mathrm{R}_{\mathrm{i}}\right) \quad$ : Expected return sekuritas ke-i pada periode ke- $\mathrm{t}$ 
a. Pendapatan saham yang sebenarnya (actual return)

Actual return merupakan pendapatan yang telah diterima investor berupa capital gain yang didapatkan dari perhitungan sebagai berikut:

$$
\mathbf{R}_{\mathrm{i}, \mathrm{t}}=\frac{\mathbf{P}_{\mathbf{t}}-\mathbf{P}_{\mathrm{t}-1}}{\mathbf{P}_{\mathrm{t}-1}}
$$

Dimana:

$\mathrm{R}_{\mathrm{i}, \mathrm{t}} \quad$ : Actual return saham perusahaan i pada bulan ke- $\mathrm{t}$

$\mathrm{P}_{\mathrm{t}} \quad$ : Harga saham pada bulan ke- $\mathrm{t}$

$\mathrm{P}_{\mathrm{t}-1} \quad$ : Harga saham pada bulan $\mathrm{t}-1$

b. Pendapatan saham ekspektasi (expected return)

Model yang digunakan untuk mengestimasi besarnya return yang diharapkan oleh investor adalah Capital Asset Pricing Model (CAPM) yang dinyatakan oleh Ross, Westerfield dan Bradford (2008) dengan model sebagai berikut:

$$
\mathbf{R}_{\mathrm{i}}=\mathbf{R}_{\mathbf{f}}+\boldsymbol{\beta}_{\mathrm{i}}\left[\mathbf{R}_{\mathrm{m}}-\mathbf{R}_{\mathrm{f}}\right]
$$

Dimana:

$\mathrm{R}_{\mathrm{i}} \quad$ : expected return dari aset $\mathrm{i}$

$\mathrm{R}_{\mathrm{f}} \quad$ : tingkat return bebas risiko/risk-free rate (tingkat suku bunga

SBI) $\mathrm{R}_{\mathrm{m}}$ : expected return dari portfolio pasar yang dihitung dengan cara :

$$
\mathbf{R}_{\mathbf{m}}=\underset{\mathbf{I H S G}_{\mathbf{t}-1}}{\left(\mathbf{I H S G}_{\mathbf{t}-1}\right)}
$$

dimana:

IHSG $_{\mathrm{t}} \quad$ : Indeks Harga Saham Gabungan pada bulan ke-t

IHSG $_{\mathrm{t}-1} \quad$ : Indeks Harga Saham Gabungan pada bulan $\mathrm{t}-1$

$\left[\mathrm{R}_{\mathrm{m}}-\mathrm{R}_{\mathrm{f}}\right] \quad$ : market risk premium

$\beta_{\mathrm{i}} \quad$ : systematic risk dari aset i terhadap portfolio pasar, yang

dihitung

dengan cara:

$$
\boldsymbol{\beta}_{\mathrm{i}}=\frac{\operatorname{Cov}\left(\mathbf{R}_{i}, \mathbf{R}_{M}\right)}{\delta^{2}{ }_{M}}
$$

dengan $\boldsymbol{\delta}^{2}{ }_{\mathbf{M}}=$ variance dari portfolio pasar

2) Unexpected Earning (UE)

Unexpected Earning diukur menggunakan pengukuran Suaryana (2004):

$$
\begin{array}{r}
\mathbf{U E} \mathbf{E}_{\mathrm{i}, \mathrm{t}}=\left(\mathbf{E}_{\mathrm{i}, \mathrm{t}}-\mathbf{E}_{\mathrm{i}, \mathrm{t}-\mathrm{t}}\right) \\
\mathbf{E}_{\mathrm{i}, \mathrm{t}-\mathbf{1}}
\end{array}
$$


Dimana:

$\mathrm{UE}_{\mathrm{i}, \mathrm{t}} \quad$ : Unexpected earning perusahaan i pada periode $\mathrm{t}$

$\mathrm{E}_{\mathrm{i}, \mathrm{t}} \quad$ : Laba akuntansi perusahaan i pada periode $\mathrm{t}$

$\mathrm{E}_{\mathrm{i}, \mathrm{t}-1} \quad$ : Laba akuntansi perusahaan i pada periode $\mathrm{t}-1$

Koefisien ERC dapat dicari dengan persamaan regresi linear sederhana dengan Unexpected Earning (UE) sebagai variabel independen dan Cumulative Abnormal Return (CAR) sebagai variabel dependen yang menghasilkan ERC untuk masingmasing sampel. Persamaan regresinya sebagai berikut:

Dimana:

$$
\mathrm{CAR}_{\mathrm{i}, \mathrm{t}}=\alpha_{0}+\alpha_{1} \mathrm{UE}_{\mathrm{i}, \mathrm{t}}+\varepsilon_{\mathrm{i}, \mathrm{t}}
$$

$\mathrm{CAR}_{\mathrm{i}, \mathrm{t}}$ : cumulative abnormal return perusahaan i pada periode $\mathrm{t}$

$\mathrm{UE}_{\mathrm{i}, \mathrm{t}} \quad$ : unexpected earning perusahaan i pada periode $\mathrm{t}$

$\varepsilon_{\mathrm{i}, \mathrm{t}} \quad$ : komponen error perusahaan i dalam model pada periode $\mathrm{t}$

$\alpha_{0} \quad$ : nilai ERC

\section{Metode Analisis Data}

Untuk menganalisis pengaruh kompensasi, kecurangan laporan keuangan dan efektifitas komite audit terhadap kualitas laba, maka metode analisis yang digunakan adalah analisis regresi linear berganda dengan menggunakan bantuan perangkat lunak (software) program Statistical Product and Service Solutions (SPSS) versi 20. Penggunaan uji regresi linear berganda harus melalui uji kualitas data sebagai persyaratan uji regresi linear berganda. Berikut persamaan regresi berganda untuk model penelitian berdasarkan hipotesis yang diajukan :

$$
K_{t}=a+b_{1} K M P_{1}+b_{2} K_{L} K_{2}+b_{3} E_{1} A_{3}+e
$$

Dimana: $\quad \mathrm{KL} \quad=$ pertumbuhan laba operasional

$\mathrm{KMP}=$ pembiayaan murabahah

KLK = risiko pembiayaan murabahah

EKA = efektivitas komite audit

e $\quad=$ error

\section{ANALISIS DAN PEMBAHASAN}

\section{Statistik Deskriptif}

Analisis deskriptif dilakukan untuk memberikan gambaran atau deskripsi dari data-data dalam penelitian ini. Analisis deskriptif dapat dilihat dalam tabel 1 berikut ini. 
Tabel 1

Statistik Deskriptif

\begin{tabular}{|c|c|c|c|c|c|}
\hline & $\mathrm{N}$ & Minimum & Maximum & Mean & Std. Deviation \\
\hline $\mathrm{KL}$ & 11 & 9529349947905 & .4703218092 & .010151840005 & .1305753355014 \\
\hline & 0 & $\begin{array}{r}\mathrm{E} \\
-1\end{array}$ & 69 & 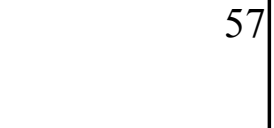 & 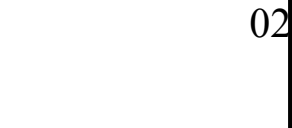 \\
\hline KMP & $\begin{array}{c}11 \\
0\end{array}$ & .4 & 798.0 & 22.323 & 77.3649 \\
\hline EKA & $\begin{array}{c}11 \\
0\end{array}$ & 1 & 33 & 6.18 & 4.158 \\
\hline $\begin{array}{l}\text { Valid N } \\
\text { (listwise) }\end{array}$ & $\begin{array}{c}11 \\
0\end{array}$ & & & & \\
\hline
\end{tabular}

Variabel Kualitas Laba (KL) memiliki nilai minimum sebesar 0,9529349947905 dan nilai maksimum sebesar 0,470321809269. Sementara, nilai mean yang diperoleh sebesar 0,01015184000557 dan standard deviation sebesar 0,130575335501402 .

Untuk variabel Kompensasi (KMP) memiliki nilai minum 0,4 dan nilai maksimum sebesar 798 serta mempunyai nilai mean sebesar 22.323. Ada pun besaran nilai standar deviasi untuk KMP adalah 77.3649. Sedangkan, nilai minimun untuk variabel Efektivitas Kualitas Audit (EKA) sebesar 1 dan nilai maksimum sebesar 33 serta nilai mean yang diperoleh adalah 6,18. Nilai standar deviasi untuk EKA adalah 4.158.

\section{Statistik Inferensial}

Uji Asumsi Klasik

\section{Uji Normalitas Data}

Uji normalitas bertujuan untuk menguji apakah dalam model regresi, variabel residual memiliki distribusi normal. Uji mormalitas yang digunakan dalam penelitian ini adalah uji Kolmogorov-Smirnov. Data dikatakan berdistribusi normal jika nilai signifikansi (p-value) yang diperoleh lebih besar dari nilai signifikansi yang ditetapkan sebelumnya $(\alpha)$, yaitu $5 \%$. 
Tabel 2

Uji Normalitas

One-Sample Kolmogorov-Smirnov Test

\begin{tabular}{|ll|r|}
\hline & & $\begin{array}{r}\text { Unstandardiz } \\
\text { ed Residual }\end{array}$ \\
\hline $\mathrm{N}$ & Mean & 110 \\
Normal Parameters & & .0000000 \\
& Std. Deviation & .08980217 \\
Most & Absolute & .125 \\
Extreme & Positive & .124 \\
Differences & Negative & -.125 \\
& & 1.313 \\
Kolmogorov-Smirnov Z & .064 \\
Asymp. Sig. (2- & \\
tailed) & \\
\hline a. Test distribution is Normal. & \\
\hline
\end{tabular}

Gambar 1

Normal Plot Regression

Normal P-P Plot of Regression Standardized Residual

Dependent Variable: KL

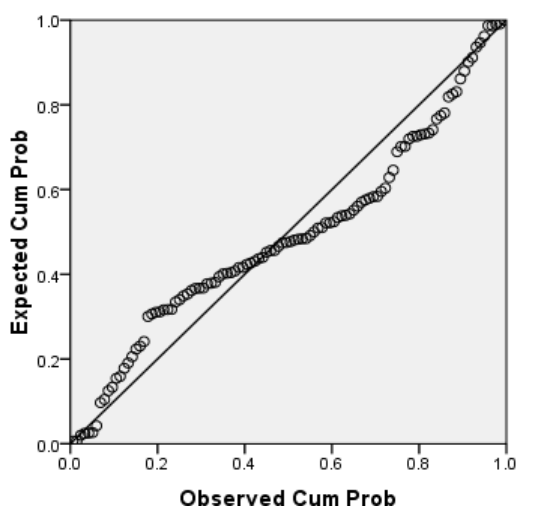

Dari hasil pengujian pada Tabel 2, diketahui bahwa pengujian model penelitian diperoleh hasil 0,064. Hasil yang diperoleh lebih besar dari 5\%, maka data berdistribusi normal.

\section{Uji Multikolinieritas}

Uji ini dilakukan untuk mendeteksi korelasi antar variabel independen. Pengujian ini akan menghasilkan nilai Variabel Inflation Factor (VIF) 
yang digunakan sebagai indikator. Nilai VIF yang ditetapkan dalam penelitian ini adalah 10, artinya semua variabel yang dimasukkan ke dalam mode regresi harus mempunyai nilai VIF dibawah 10. Jika nilai VIF yang diperoleh lebih besar dari 10 dan tolerance kurang dari 0,10 maka menunjukkan adanya multikoinieritas yang tinggi. Hasil uji dapat dilihat pada Tabel 3.

Tabel 3

Uji Multikolinieritas

\begin{tabular}{|ll|r|c|}
\hline \multirow{2}{*}{\multicolumn{2}{|c|}{}} & \multicolumn{2}{|c|}{ Collinearity Statistics } \\
\cline { 2 - 4 } \multicolumn{2}{|l|}{ Model } & Tolerance & VIF \\
\hline 1 & (Constant) & & \\
& KMP & .999 & 1.001 \\
& KLK & .995 & 1.005 \\
& EKA & .996 & 1.004 \\
\hline
\end{tabular}

Dari hasil uji multikolinieritas, diketahui bahwa tidak ada variabel independen yang memiliki nilai tolerance kurang dari 0,1 yang berarti tidak ada korelasi antar variabel independen yang nilainya lebih dari $90 \%$. Hasil perhitungan nilai VIF juga menunjukkan hal yang sama, nilai VIF untuk variabel independen di atas tidak ada yang melebihi 10. Jadi, dapat disimpulkan tidak terdapat multikolinieritas antar variabel indepeden dalam model regresi dalam penelitian ini.

\section{Uji Autokorelasi}

Salah satu cara untuk mendeteksi ada atau tidaknya autokorelasi adalah Uji Durbin-Watson (DW). Hasil pengujian lalu dibandingkan dengan nilai DW kritis yang terdapat dalam tabel DW. Setelah itu dapat ditarik kesimpulan apakah ada atau tidak ada autokorelasi yang ditandai dengan batas atas $\left(\mathrm{d}_{\mathrm{u}}\right)$ dan batas bawah $\left(\mathrm{d}_{\mathrm{L}}\right)$ dari hasil pengujian tersebut. 


\section{Uji Autokorelasi Model Summary}

\section{Tabel 4}

\begin{tabular}{|c|c|c|c|c|c|}
\hline Model & $\mathrm{R}$ & R Square & $\begin{array}{l}\text { Adjusted } \\
\text { R } \\
\text { Square }\end{array}$ & $\begin{array}{l}\text { Std. Error } \\
\text { of the } \\
\text { Estimate }\end{array}$ & $\begin{array}{l}\text { Durbin- } \\
\text { Watson }\end{array}$ \\
\hline $\begin{array}{l}\text { a. Prec } \\
\mathrm{K} \perp K\end{array}$ & $\begin{array}{r}\text { ctors: }(\mathrm{Co} \\
726^{\mathrm{a}} \\
\end{array}$ & \begin{tabular}{|r|} 
nstant), EK \\
527 \\
\end{tabular} & \begin{tabular}{|l|} 
A, KMP, \\
\end{tabular} & .09106408473 & 2.15 \\
\hline
\end{tabular}

Uji Durbin Watson untuk model penelitian didapatkan hasil sebesar 2,152. Peneliti membandingkan nilai tersebut dengan nilai yang terdapat dalam tabel Durbin-Watson dengan menggunakan signifikansi sebesar 5\%, jumlah sampel 110, $\mathrm{k}^{\prime}=4$. Maka dari tabel Durbin Watson didapatkan nilai $d_{L}=1,6146$ dan $d_{u}=1,7651$ Sehingga, diperoleh nilai $4-d_{u}$ sebesar 2,2349 dan 4- $\mathrm{d}_{\mathrm{L}}$ sebesar 2,3854. Berdasarkan hasil pengujian didapatkan nilai DW model berada di daerah no auto. Oleh karena itu dapat ditarik kesimpulan bahwa model dalam penelitian ini bebas autokorelasi.

\section{Uji Heteroskedastisitas}

Uji heteroskedastisitas ini bertujuan menguji apakah terjadi ketidaksamaan varians dan residual satu pengamatan ke pengamatan lain. Jika menghasilkan pengamatan yang tetap, maka terjadi homokedastisitas dan ini baik bagi suatu model regresi.

Tabel 5

Uji Heteroskedastisitas

\begin{tabular}{|c|c|c|c|c|c|c|}
\hline \multirow{2}{*}{\multicolumn{2}{|c|}{ Model }} & \multicolumn{2}{|c|}{$\begin{array}{l}\text { Unstandardized } \\
\text { Coefficients }\end{array}$} & \multirow{2}{*}{$\begin{array}{l}\text { Standardize } \\
\text { d } \\
\text { Coefficients } \\
\text { Beta }\end{array}$} & \multirow{2}{*}{$\mathrm{t}$} & \multirow{2}{*}{ Sig. } \\
\hline & & B & Std. Error & & & \\
\hline \multirow[t]{4}{*}{1} & (Constant) & .043 & .011 & & 3.937 & .000 \\
\hline & KMP & $-8.881 \mathrm{E}-6$ & .000 & -.010 & -.114 & .909 \\
\hline & KLK & .089 & .029 & .283 & 3.076 & .003 \\
\hline & EKA & .002 & .001 & .147 & 1.596 & .113 \\
\hline
\end{tabular}

a. Dependent Variable: ABSRES

Nilai signifikansi variabel independen pada model penelitian ini di atas 0,05, kecuali variabel Kecurangan Laporan Keuangan (KLK) yang di 
bawah 0,05. Maka dapat disimpulkan bersifat homokedastisitas dan bebas heteroskedastisitas. Variabel KLK (Kecurangan Laporan Keuangan) mempunyai signifikansi 0,003 diabaikan karena skala pengukurannya nominal.

\section{Uji Goodness-of-Fit}

Pengujian goodness-of-fit digunakan untuk melihat seberapa besar kecocokan model penelitian. Pengujian fit model dalam regresi linier dapat diketahui dengan uji $\mathrm{F}$ dan melihat nilai $\mathrm{R}^{2}$ (koefisien determinasi). Hasil Uji $\mathrm{F}$ dapat dilihat pada Tabel 6.

\section{Tabel 6}

Uji F Pada Model ANOVA ${ }^{b}$

\begin{tabular}{|c|c|c|c|c|c|}
\hline Model & $\begin{array}{l}\text { Sum of } \\
\text { Squares }\end{array}$ & df & $\begin{array}{l}\text { Mean } \\
\text { Squar } \\
\mathrm{e}\end{array}$ & $\mathrm{F}$ & Sig. \\
\hline 1 Regression & ant), EKA, ${ }_{, 879} \mathrm{~K}_{9}$ & IP, KLF & $\begin{array}{l}326 \\
, 008\end{array}$ & 39,369 &, $000^{\mathrm{a}}$ \\
\hline
\end{tabular}

Dari tabel ANOVA terdapat nilai F untuk penelitian ini sebesar 39,369 dan nilai signifikansi sebesar 0,000. Karena nilai signifikansi lebih kecil daripada 0,05 maka model penelitian ini memenuhi syarat (Fit Model).

Tabel 7

Koefisien Determinasi

\begin{tabular}{|c|c|c|c|c|c|}
\hline Model & $\mathrm{R}$ & R Square & $\begin{array}{l}\text { Adjusted } \\
\text { R } \\
\text { Square }\end{array}$ & $\begin{array}{l}\text { Std. Error } \\
\text { of the } \\
\text { Estimate }\end{array}$ & $\begin{array}{l}\text { Durbin- } \\
\text { Watson }\end{array}$ \\
\hline 1 & $\begin{array}{l}.726 \\
\mathrm{a}\end{array}$ & .527 & .514 & $\begin{array}{r}.091064084736 \\
317\end{array}$ & $\begin{array}{l}2.15 \\
2\end{array}$ \\
\hline
\end{tabular}

Berdasarkan Tabel 7 di atas diperoleh untuk model penelitian nilai Adjusted $\mathrm{R}^{2}$ sebesar 51,4\%. Hasil tersebut berarti variabel Kompensasi, Kecurangan Laporan Keuangan dan Efektivitas Komite Audit dapat menjelaskan Kualitas Laba sebesar 51,4\% dan 48,6\% dijelaskan oleh variabel lainnya. 


\section{Uji Hipotesis}

Uji hipotesis dalam penelitian ini untuk menguji pengaruh Kompensasi, Kecurangan Laporan Keuangan dan Efektivitas Komite Audit pada Kualitas Laba.

Penelitian ini dibagi menjadi 3 hipotesis. Hasil uji t dapat dilihat pada tabel di bawah ini:

Tabel 8

Uji Hipotesis

\begin{tabular}{|c|c|c|c|c|c|c|}
\hline \multirow{2}{*}{\multicolumn{2}{|c|}{ Model }} & \multicolumn{2}{|c|}{$\begin{array}{c}\text { Unstandardized } \\
\text { Coefficients }\end{array}$} & \multirow{2}{*}{$\begin{array}{l}\text { Standardize } \\
\text { d } \\
\text { Coefficients } \\
\text { Beta }\end{array}$} & \multirow{2}{*}{$\mathrm{t}$} & \multirow{2}{*}{ Sig. } \\
\hline & & B & Std. Error & & & \\
\hline \multirow[t]{4}{*}{1} & (Constant) & .010 & .016 & & .658 & .512 \\
\hline & KMP & -.001 & .000 & -.701 & -10.486 & .000 \\
\hline & KLK & .078 & .042 & .124 & 1.856 & .066 \\
\hline & EKA & .004 & .002 & .116 & 1.738 & .085 \\
\hline
\end{tabular}

. Dependent Variable: KL

Dari hasil uji hipotesis pada model di atas, dapat dilihat bahwa nilai signifikansi untuk Kompensasi (KMP) sebesar 0,000; koefisien regresi sebesar 0.001. Nilai signifikansi ini lebih kecil dari 10\% dan koefisien regresi bertanda negatif, sehingga dapat disimpulkan hipotesis kompensasi berpengaruh positif pada kualitas laba dapat diterima. Sedangkan, nilai signifikansi untuk Kecurangan Laporan Keuangan (KLK) sebesar 0,66 dan koefisien regresi 0,078. Hasil ini menunjukan bahwa variabel KLK memiliki nilai signifikansi lebih kecil dari 10\% dan koefisien regresi bertanda positif yang berarti hipotesis kecurangan laporan keuangan berpengaruh negatif pada kualitas laba tidak dapat diterima. Demikian juga untuk variabel Efektivitas Komite Audit (EKA) memiliki nilai signifikansi sebesar 0,85 dan koefisien regresi sebesar 0,004. Hal ini menandakan bahwa variabel EKA mempunyai nilai signifikansi di bawah $10 \%$ dan koefisien regresi yang positif sehingga dapat disimpulkan bahwa hipotesis efektifitas komite audit berpengaruh positif pada kualitas laba dapat diterima.

\section{Pembahasan}

Hasil pengujian hipotesis kompensasi berpengaruh negatif dalam penelitian ini terbukti. Hasil ini menunjukkan sikap oportunis manajemen sebagai wujud moral hazard dalam teori keagenan merupakan sinyal negatif bagi investor (Jensen dan Meckling, 1976; Srinivasan, 2005; Bebchuk dan Fried, 2006).

Perusahaan yang melakukan praktek kecurangan berpengaruh negatif dengan kualitas laba. Namun demikian hasil penelitian mengindikasikan bahwa 
perusahaan yang melakukan kecurangan atas laporan keuangan mempunyai probabilitas lebih besar untuk mendapatkan respon positif dari investor. Hasil ini bertolak belakang dengan teori sinyal yang menyatakan bahwa kecurangan laporan keuangan merupakan sinyal negatif bagi investor, bahkan Kalbers (2009) mengatakan bahwa laba dengan kualitas tinggi mengindikasikan adanya kecurangan. Hasil positif signifikan dalam penelitian ini disebabkan sudah adanya tata kelola yang baik pada perusahaan yang listing di Bursa Efek Indonesia, kecurangan laporan keuangan hanya dilakukan sebanyak $5 \%$ dari perusahaan sampel.

Hipotesis yang menguji pengaruh positif efektivitas komite audit pada kualitas laba terbukti dalam penelitian ini. Hasil ini konsisten dengan pendapat Niu (2006), Petra (2007), Chen et.al. (2014), Carcello dan Neal (2000) dan Anderson (2003).

\section{KESIMPULAN DAN SARAN}

\section{Kesimpulan}

Penelitian ini membuktikan bahwa hasil pengujian dari ketiga hipotesis yang diajukan adalah dua hipotesis dapat diterima dan satu hipotesis ditolak. Kedua hipotesis yang diterima adalah variabel kompensasi berpengaruh negatif terhadap kualitas laba dan efektifitas komite audit berpengaruh positif terhadap kualitas laba. Sedangkan, hipotesis yang ditolak adalah kecurangan laporan keuangan berpengaruh negatif terhadap kualitas laba.

\section{Keterbatasan dan Saran}

Kecurangan dalam penelitian ini diukur dengan ada dan tidaknya informasi kecurangan yang dirilis oleh Bapepam (OJK) sehingga kurang mencerminkan praktik kecurangan yang ada di dalam perusahaan. Selain itu, penelitian ini menguji tata kelola perusahaan hanya berdasarkan efektifitas komite audit.

Untuk penelitian selanjutnya disarankan menggunakan proksi lain untuk variabel kecurangan laporan keuangan, misalnya membuat skoring berdasarkan rata-rata praktik industri dengan skor perusahaan. Sedangkan, mekanisme tata kelola perusahaan selain efektifitas komite audit, peneliti menyarankan seperti proporsi komisaris independen, keahlian komite audit. 


\section{DAFTAR PUSTAKA}

Anderson, S., \& J. Cavanagh. 2003. Executive Excess 2003: CEO's win, workers and taxpayers lose. Retrieved May 4, 2012, dari http://www.faireconomy.org/files/Executive Excess_2003.pdf

Arrmstrong, Christopher S.; Jagolinzer, Alan D.; Larcker, David F. 2010. Chief Executive Officer Equity Incentives and Accounting Irregularities. Journal of Accounting Research 48 (2):225-271.

Bao, B dan Bao, D. 2004. Income Smoothing, Earnings Quality dan Firm Valuation. Journal of Business Finance \& Accounting, 31 (9) \& (10). November/December.

Beasley, M. S. 1996. An Empirical Analysis of the Relation between the Board of Director Composition and Financial Statement Fraud. The Accounting Review, 71(4): 443-465.

Beasley, M., J. Carcello, D. Hermanson dan T. Neal. 2010. Fraudulent Financial Reporting, 1987-1997: An Analysis of U.S. Public Companies. New York, NY: Committee of Sponsoring Organization of the Treadway Commission.

Bebchuck, Lucian A. \& Jesse M. Fried. 2004. Pay without Performance: The Unfulfilled Promise of Executive Compensation. Harvard University Press.

Bebchuk, L. A., \& Fried, J. M. 2006. Pay without Performance: Overview of the Issues. Academy of Management Perspectives, 20 (1): 5-24.

Berle, A. dan Means, G. 1932. The Modern Corporation and Private Property. Macmillan, New York, NY.

Boyle, D. M., Brian W. Carpenter dan Dana R. Hermanson. 2012. CEOs, CFOs and Accounting Fraud: Implications of Recent Research. The CPA Journal (January): 62-65.

Brick, I .E., O. Palmon, \& J. K. Wald. 2006. CEO Compensation, Director Compensation, and Firm Performance: Evidence of Cronyism? Journal of Corporate Finance, 12(3), 403-423.

Brown, L D., dan Sivakumar, K, 2001. Comparing the quality of Three Earning Measures. Working Paper. Georgia State University. Atlanta, GA 30303.

Coles, J. L., N.D. Daniel, and L Naveen. 2006. Managerial incentives and risk taking. Journal of Financial Economics 79: 431-468.

Collins, D. dan W. Salatka. 1993. Noisy Accounting Earning Signals and Earning Response Coefficients: The Case of Foreign Currency Accounting. Contemporary Accounting Research 10 (1).

Collins, Daniel, Edward Maydew, and Ira Weiss. 1997. Changes in the valuerelevance of earnings and book values over the past forty years. Journal of Accounting and Economics:39-67.

Cornell, B. dan W.R. Landsman. 2003. Accounting Valuation: Is earning Quality an Issue?. Financial Analysis Journal. November/December.

Dechow, P. M., R. G. Sloan \& A. P. Sweeney. 1996. Causes and Consequences of earningsManipulation: An Analysis of Firms Subject to Enforcement Actions by the SEC. Contemporary Accounting Research, 13(1), 1-36.

Deegan, C. 2004. Financial Accounting Theory. McGraw-Hill Book Company. Sydney. 
Dorminey, W. J., Arron Scott Fleming, Marry-Jo Kranacher \& Richard A. Riley, Jr. 2012. Financial Fraud. The CPA Journal (June): 61-65.

Ecker, F.,Francis, J., Kim, I., Olsson, P. \& Schipper, K. 2006. A Return-Based Representation of Earnings Quality. The Accounting Review, 81: 749-780.

Efendi, J., A. Srivastava dan E. Swanson. 2007. Why Do Corporate Managers Misstate Financial Statements? The Role of Option Compensation and Other Factors. Journal of Financial Economics 85 (3): 667-708.

Eisenhardt, K. M. 1989. Agency Theory: An Assessment and Review. Academy of Management Review, 14(1): 51-1 A.

Elliot, Robert K. \& John Wilingham. 1980. Management Fraud: Deterrents and Detection. Petrocelli Books.

Erickson, M., M. Hanlon, and E. L. Maydew. 2006. Is There a Link Between Executive Equity Incentives and Accounting Fraud?. Journal of Accounting Research 44 (1): 113-143.

Fama, E. 1980. Agency Problems and the Theory of the Firm. Journal of Political Economy 88: 288-307.

Fama, Eugene F., and Michael C. Jensen. 1983. Separation of Ownership and Control. Journal of Law and Economics, 26 (June): 301-325.

Farrar, J. H. 2001. Corporate Governance in Australia and New Zealand. Singapore: Oxford University Press.

Francis, J \& Schipper, K. 1999. Have financial statements lost their relevance. Journal of Accounting Research 37(2):319 - 352.

Hogan, C. E., Z. Rezaee, R. A. Riley dan U. K. Velury. 2008. Financial Statement Fraud: Insights from the Academic Literature. Auditing: A Journal of Practice \& Theory 27 (2): 231-252.

Hoi, Chun-Keung \& Ashok Robin. 2004. The Design of Incentive Compensation for Directors. Corporate Governance, 4 (3): 47-53.

Jensen, M. 1993. The Modern Industrial Revolution, Exit, and Failure of Internal Control Systems. Journal of Finance, 48(3), 831-880.

Jensen, M. dan W. Meckling. 1976. Theory of the Firm: Managerial Behaviour, Agency Costs and Ownership Structure. Journal of Financial Economics 3: 305-60.

Johson, S. A., H. E. Ryan, Jr \& Yisong S. Tian. 2005. Executive Compensation and Corporate Fraud. Working Paper.

Kalbers, Lawrence P. 2009. Fraudulent financial reporting, corporate governance and ethics: 1987-2007. Review of Accounting and Finance, Vol. 8 Iss: 2, pp. $187-209$.

Kinney, W. dan Linda McDaniel. 1989. Characteristics of Firms Correction Previously Reported Quarterly Earnings. Journal of Accounting and Economics 32: 45-60.

Murphy, Kevin J. 2002. Explaining executive compensation: Managerial power versus the perceived cost of stock options. The University of Chicago Law Review 69 (3), Summer: 847-869.

Nagar, Venky. 2002. Delegation and incentive compensation. The Accounting Review 77 (2): 379-395. 
Nguyen, Khanh. (2008). Financial Statement Fraud: Motives, Methods, Cases and Detection. USA : Boca Raton, Florida.

Penman, S. H; dan Zhang, X. 2002. Accounting Conservatism, The Quality Of Earnings, And Stock Returns. The Accounting Review, April 77 (2).

Srinivasan, S. 2005. Consequences of Financial Reporting Failure for Outside Directors: Evidence from Accounting Restatements and Audit Committee Members. Journal of Accounting Research, 43(2): 291-334.

Trompeter, G. M.; Carpenter, Tina D.; Desai, Naman; Jones, Keith L.; Riley Jr., Richard A. 2013. A Synthesis of Fraud-Related Research. Auditing. Supplement 1, Vol. 32, p287-321. 35p. 1 Diagram. DOI: 10.2308/ajpt-50360.

Wild, J. J. 1996. The Audit Committee and Earnings Quality. Journal of Accounting, Auditing \& Finance (Spring): 247-276.

Winter, N. 2003. Fair Pay for Fair Play. CA Magazine, 136 (10), 34.

$\mathrm{Wu}$, Min, 2002, Earnings restatements: A capital market perspective, $P h D$ dissertation, New York University 